\title{
THE CLINICAL CHARACTERISTICS, TREATMENT, AND REHABILITATION OF REPATRIATED PRISONERS OF WAR WITH NEUROSIS
}

\author{
BY \\ MAXWELL JONES and J. M. TANNER \\ From the Mill Hill Emergency Hospital and Neurosis Unit, Southern Hospital, \\ Dartford, Kent
}

(RECEIVED FOR PUBLICATION, SEPTEMBER 10, 1947)

\section{Introduction}

At the end of May, 1945, we were seconded from Mill Hill Emergency Hospital to start a neurosis centre for repatriated prisoners of war at Dartford, Kent. During the following eight months 811 repatriates from the North-west Europe sector passed through the unit. This paper describes the clinical characteristics of these men, their treatment and rehabilitation, and the results of a short-term follow-up on a sample of them.

The patients were referred to us by the psychiatrists of the 45th Division, who handled the psychiatric problems of the 100,000 British repatriates from Europe. They were men who had shown signs of psychological maladjustment on repatriation, during the repatriation leave, or on returning to their unit after the leave. Mild cases were dealt with on the spot, so that the material sent to us constituted the most maladjusted 1 per cent. of the entire prisoner-of-war group. There were no officers sent to our unit.

The subject is discussed under four headings : clinical characteristics, treatment, follow-up, and general discussion.

\section{Clinical Characteristics}

We were already familiar with the main problems facing this group, having seen some twenty patients who had escaped or been repatriated on medical grounds. Based on this experience, a standard case form was drawn up, which we hoped would supply us with the usual psychiatric case data, and also allow us to analyse the results by statistical methods. In order to obtain as much objective information about these patients as possible, we studied in a sample group the physiological response to a standard exercise on a bicycle ergometer, their persistence as measured by leg-raising and breath-

G holding tests, their suggestibility by the body sway test, and their physique. The details of symptomatology and the exercise response, and the interrelations between these two and physique are discussed in the paper at p. 61 of this issue (Tanner and Jones, 1948) ; only the main results necessary for the understanding of the clinical problem are given here.

The symptoms and history of a sample of 100 of these 811 men were studied. Fifty were seen by each psychiatrist, and the 100 were chosen simply as every fifth admission to the unit. They were examined during the period June to September, 1945. The mean age of the 100 was $27 \cdot 3$, with a standard deviation of $4 \cdot 0$ years. Excluding eight old soldiers, the average time of army service was five and a half years, with a standard deviation of one year. An average of four years had been spent overseas, and three and a half years as prisoner of war. No significant differences exist between the two groups of 50 in age, time of service, or of imprisonment, physique, oxygen consumption followirlg standard exercise, and other physiological tests. Despite an alternating method of selection, however, the groups differed in intelligence (progressive matrices test, $\mathbf{P}<\cdot 01$ ).

Case Form.-The form used followed the familiar pattern of a case history, divided into the three main sections, pre-army, army service, and present illness. At the end of each of these sections certain summarizing items were rated, using a seven-point interval scale, in which a score of one represented the minimal, and seven the maximal degree of severity.

1. Pre-army Record.- - Under this heading were considered family history, personal history (home atmosphere, social circumstances, schooling, work record, sexual and marital history), and personality (social adjustment, adaptability, range of interests, temperament, intelligence, physique, etc.). At the end of this enquiry (or later in summarizing the entire history) ratings were made of environmental stress, constitutional predisposition to breakdown, heredity, total stress to 
time of joining army, and stress reaction up till this time, that is, the amount of neurotic symptomatology which had occurred. Table I shows the mean ratings of each investigator in these traits, the rating 1 symbolizing little stress, little predisposition, etc.

\section{TABLE I}

PRE-ARMY RATINGS

\begin{tabular}{|c|c|c|c|c|c|}
\hline \multicolumn{4}{|c|}{ 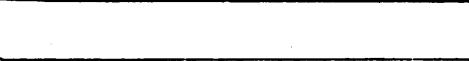 } & M.J. & J.T. \\
\hline \multirow{2}{*}{\multicolumn{3}{|c|}{$\begin{array}{l}\text { Environmental stress } \\
\text { Constitutional predisposition }\end{array}$}} & . & 1.9 & $3 \cdot 7$ \\
\hline & & & • & $2 \cdot 1$ & $3 \cdot 2$ \\
\hline Heredity & .. & .. & .. & $1 \cdot 9$ & $2 \cdot \overline{4}$ \\
\hline Total stress .. & . & .. & .. & $1 \cdot 7$ & $3 \cdot 5$ \\
\hline Stress reaction & .. & .. & .. & $1 \cdot 5$ & $2 \cdot 2$ \\
\hline
\end{tabular}

It is unfortunate that we have to present this table first : these ratings, in fact, are the only ones, out of a total of 86 , for which the investigators do not agree, and that quite closely. The agreement and reliability of the ratings are discussed in the second paper. After initially discussing the case form, and our definitions, we did not at any time, formally or informally, discuss ratings or our results, and in this particular instance it led to misunderstanding. M. J. rated pre-army traits in relation to what was expected of a neurotic population (whose mean would thus be about 3.5 ), while J. T. rated them in relation to a normal group. When this is borne in mind the conclusions appear consistent and obvious, and they were supported by the unanimous opinion of the rest of the unit's staff : these patients had not the constitutional predisposition of the usual neurotic seen in neurosis centres, and were only very slightly, if at all, more predisposed than the normal citizen. They had been subjected to no abnormal stresses in civil life, and in conformity with this, had shown no degree of neurotic response.

2. Army Service.-Following a history of army and P.O.W. life, ratings of the following were made : precapture army adjustment, unsuitable work in army, home worries, active service physical danger, physical health, prisoner-of-war camp stress, repatriation stress (home and army). The prisoner-of-war camp stress was rated according to the patient's own account of his prison life, but with reference to the objective stress as presumed by the investigator, rather than the repatriate's subjective rating of it. Thus a man who stayed permanently in one camp and was only very slightly starved and never suffered or witnessed any brutaliites was rated 1, while a man who had been shifted from place to place, starved, marched across Germany and beaten up got a higher rating. Table II shows these items.

Though it would not necessarily follow from the manner of making the ratings, we feel that the order of importance of the various items is as appears in the Table. The agreement between raters is satisfactory here. Most important in causing breakdown were the stresses of the camp (and in particular the last six months, with the dislocation of food service, the forced marches,
TABLE II

ARMY SERVICE

\begin{tabular}{|c|c|c|c|c|c|}
\hline \multirow{2}{*}{\multicolumn{3}{|c|}{$\begin{array}{l} \\
\text { Prisoner-of-war camp stress } \\
\text { Repatriation stress (army) } \\
\text { Repatriation stress (home) } \\
\text { Active service danger }\end{array}$}} & & $\mathbf{M}: \mathbf{J}$. & J. T. \\
\hline \multirow{4}{*}{\multicolumn{3}{|c|}{$\begin{array}{l}\text { Prisoner-of-war camp stress } \\
\text { Repatriation stress (army) } \\
\text { Repatriation stress (home) }\end{array}$}} & & $3 \cdot 6$ & $3 \cdot 5$ \\
\hline & & & $\cdots$ & $3 \cdot 5$ & 3.7 \\
\hline & & & & $3 \cdot 3$ & 3.9 \\
\hline & & & . & $2 \cdot 9$ & $3 \cdot 0$ \\
\hline Physical health &.. & $\ddot{m}$ & $\ddot{\cdots}$ & $2 \cdot 3$ & $2 \cdot 5$ \\
\hline Army adjustment & $\begin{array}{l}\cdots \\
. .\end{array}$ & $\ddot{m}$ & $\ddot{\cdots}$ & $2 \cdot 0$ & $2 \cdot 5$ \\
\hline Home worries & $\ddot{m}$ & $\ddot{0}$ & $\ddot{m}$ & 1.8 & $2 \cdot 0$ \\
\hline Unsuitable work & $\ddot{0}$ & $\ddot{m}$ & $\cdots$ & $1 \cdot 3$ & 1.9 \\
\hline
\end{tabular}

and the bombing), and the difficulties in adjustment both to home and army conditions. The army adjustment of these men, as might be anticipated, was relatively good, and 65 per cent. stated they could think of no better employment in the army than that which had been chosen for them.

The men were also asked to state the three most severe stresses they had been subjected to while in the army. As one of the three 58 per cent. mentioned poor food at the beginning and end of captivity, 30 per cent. stress of active service, 26 per cent. allied bombing as prisoners of war, and 24 per cent. the conditions on the marches at . beginning and end of captivity. In response to the specific questions in the case form, 88 per cent. state $\bar{\omega}$ that sex per se (that is, the lack of intercourse) was nes real problem for them while prisoners. This reaction in marked contrast to that following deprivation of $T$ food, when dreams of eating food and group discussions $\frac{D}{O}$ at which such men as butchers and bakers describeg at length and in detail their dealings with food were common. Eighty-two per cent. said enemy propagand장. had no effect on them at all (partly because of the nearly universal access to an illicit radio and British news) and 58 per cent. said they had been subjected to no unreasonable degree of punishment or cruelty.

3. Symptomatology.-The account of the present $\overline{\bar{O}}$ illness was extended by enquiry about the presence and severity of a total of 64 symptoms, set out in detail in the subsequent paper. There was very good agreement $\overrightarrow{\vec{B}}$ between the investigators on the ratings, and in particular those for the more marked symptoms. Only two symptoms were given a mean rating of over 3.0 by each investigator: these were lack of concentration and depression. The following were given ratings of over 2.5 by one and over 3.0 by the other : feeling of not belonging since repatriation, asocial, more shy in the presence of women than previously, more easily fatigued, 3. breathlessness on effort, effort intolerance, trembling, $\delta$ and resentment towards army and authority in general. These constitute the main symptoms of our group.

Some of the symptoms which rated very low are also 윽 of interest. The following were given mean ratings of $D$ under 2.0 by both investigators : fear of impotence, actual impotence, fear of sterility, family felt to be less $\mathrm{N}$ affectionate, battle dreams, weeping, enuresis, frequency $\sigma$ of micturition, left chest pain, fainting attacks, flatulence, $\mathrm{N}$ diarrhœa, and vomiting. 
4. Clinical Score.-Finally, instead of making a clinical diagnosis, which has distinct limitations from the descriptive point of view, we rated the patient in the common designations of somatic anxiety (anxiety with somatic symptoms predominating), psychic anxiety (mental distress manifest in lack of concentration, etc.), and depression. We had no patients where the major clinical label was hysteria or psychosis. The mean ratings are shown in Table III.

\section{TABLE III}

CLINICAL SCORE

\begin{tabular}{|c|c|c|c|c|c|}
\hline & & & & M. J. & J. T. \\
\hline $\begin{array}{l}\text { Somatic anxiety } \\
\text { Psychic anxiety } \\
\text { Depression ... }\end{array}$ & $\begin{array}{l}\ldots \\
\cdots \\
\cdots\end{array}$ & $\begin{array}{l}\ldots \\
\cdots \\
\ldots\end{array}$ & $\begin{array}{l}. \\
\ddot{.}\end{array}$ & $\begin{array}{l}2 \cdot 8 \\
3 \cdot 3 \\
2 \cdot 6\end{array}$ & $\begin{array}{l}3 \cdot 1 \\
3 \cdot 4 \\
2 \cdot 6\end{array}$ \\
\hline
\end{tabular}

Physiological and Psychological Tests.-It suffices to say here that the exercise response of these patients fell mid-way between that of normal army men and the usual army neurosis centre patient. The same is true of psychometric test results (Eysenck, 1947, p. 255).

Relations between Ratings.-The correlations were calculated between the ratings on the clinical scores and various other ratings and measurements. Few of these reached significant levels, and only two relations are consistent for both investigators, and of interest. Depression correlated +0.39 with prisoner-of-war camp stress, and somatic anxiety correlated +0.38 with constitutional predisposition. It would seem from our evidence, such as it is, that reactive depression is well named. However, in view of the negative findings in the second paper, we would not lay much emphasis on this.

\section{Treatment}

General.-The unit consisted, for most of its existence, of six separate blocks of fifty beds, each with its own doctor and about six nurses. There was in addition a vocational psychologist, a fulltime disablement-rehabilitation officer (D.R.O.) of the Ministry of Labour, a psychiatric social worker, and an occupational therapist. Individual psychotherapy followed the usual lines, and physical adjuncts in treatment such as electric convulsion therapy and sodium amytal were used when indicated, which was seldom. The average time the patient stayed was six weeks, and there was only a small variation round this figure.

Each block rapidly became a small community, with its four wards as the basis for smaller groups. It was immediately and strikingly obvious that the morale of this community was of the utmost importance for the outcome of the patient's stay. Patients, particularly the older and more intelligent ones who served to induct newcomers into this new but transitional society, and also nurses contributed to the building of high morale. It was, however, chastening to observe that the chief factor was the behaviour of the psychiatrist. A falling-off of group morale was perfectly perceptible when the psychiatrist began to slacken the pace of his work, or became even mildly preoccupied with outside affairs. It appeared of more importance for him to give the appearance of caring about the welfare of his patients than actually to see them individually at frequent intervals. During the first two weeks of the unit's existence there were only two psychiatrists and a hundred patients arrived ; consequently patients waited up to ten days for their first full interview, but the doctors were on the wards for longer hours than at any subsequent time, and morale was at least as high.

Group Talks.-Each block met from 9 to 10 a.m. every day for a group discussion. These discussions were largely educational in their aims : their use has been described more fully elsewhere (Jones, 1944). Two days were devoted to talks on the structure and function of the central nervous system, and the mechanism of the production of such symptoms of anxiety as headache, fainting, left chest pain, palpitation, and indigestion. On a third morning a documentary film was shown, followed by a discussion : the films served two purposes, reorientation to present circumstances in this country (child welfare film, building trade film) and psychotherapeusis (rehabilitation of physically injured at Roehampton). The fourth morning was devoted to psychodrama, and group discussion, and the fifth to a "grouse meeting," at which the affairs of the community were discussed. This last meeting was found to be of great importance, and provided considerable opportunities for the release of aggression ; it was noticeable that by far the largest number of complaints related to food, about which, from time to time, a somewhat paranoid attitude developed, as noted by Whiles (1945).

Work Therapy and Vocational Selection.-From 10 a.m. to mid-day and from 2 to 4 p.m. the patients were taken by bus to various occupations outside the hospital. Within a few months of our arrival we had found over fifty firms and employers willing to help us in employing the patients. in a real work environment (Jones, 1946). The men were not expected to do productive work and did not replace a workman ; but they were afforded an opportunity of seeing the conditions of work in a particular trade, and were expected to lend a hand when required. The effect of this therapy was twofold. The repatriates were able, from a secure and partially secluded base, to re-enter for short testing periods 
the society they were endeavouring to return to, and to re-enter it under the natural conditions of association on a job, this helping them to overcome their withdrawn " don't belong " attitude. Second$1 \mathrm{y}$, the first-hand contact with a particular job was invaluable in those cases - and they were a majority -where the future employment goal was still uncertain. The range of choice of occupation included farming, dairy farming, market gardening, building, garage work, engineering firm work, foundry work, agricultural engineering, shipyard work, paper mills, chemical factory, printing, clerical, and numerous small shopkeeping jobs. The big factories offered many specialized jobs such as electrical maintenance, heating, print-room, and so forth, so that the total choice of occupation represented a fair cross-section of any small community. A change of job was made when a man requested it, provided the doctor and the psychologist thought it really desirable, and this practical aid to vocational selection was considered by the psychologist to be more valuable than the routine vocational aptitude tests.

Social Rehabilitation.-The repatriates were usually uneasy in crowds, and particularly shy with women. The nurses were of paramount importance in helping to overcome the men's lack of social confidence. Several writers (Newman, 1944; Torrie, 1945), one himself a prisoner of war, have emphasized the repatriate's fear of rejection by women and his feeling of inadequacy in their presence; symptoms which, if not dealt with properly, tend to generate a protective jealous, wronged, mildly paranoid outlook. The nurses, under the psychiatrists' supervision, were actively engaged in therapy at this level. They were often able, with their special training, temporarily to take the place of the repatriate's family and thus allow him to work through his initial diffidence without meeting the defensive reaction that many an uninformed and emotionally concerned wife or fiancée would have shown. We believe that far too little use of nurses has been made in psychiatry in the past; if properly trained and working in close collaboration with the doctors, they can do invaluable work at this social level. We have always held that nurses should be assigned a definite number of patients each, and should read the doctor's notes on these men, and that the doctor should have a tutorial at least once a week to supervise and give advice to the nurses on their handling of them. No attempt is made to hide these facts from the patients and it is not our experience that they resent it in the least ; on the contrary they appear to feel gratified that the nurse understands their difficulties better for her instruction. Needless to say, however, such a policy needs good nurses to carry it out, and some are found to be temperamentally unsuited to it.

The nurses ran a dancing class exclusively for nondancers, and this was found to be very popular and very excellent in its results. From it the men graduated to full participation in a fortnightly social evening. Each block invited girls from one of the local factories once a fortnight ; the patients themselves made all the arrangements for these dances, and spent long hours decorating their block and buying prizes, and organizing transport and food for their guests. These socials were as a rule very successful; the welfare officer at the factory concerned organized the party of girls sent, and explained the need to help the shy and inhibited and depressed men, as well as the more sociable patients.

Finally, social relations were frequently discussed in the groups and enacted in the plays, and further insight was fostered in this way.

Placement.-The work therapy helped greatly in determining the placement of patients when they left hospital after discharge from the army. We were fortunate in having a full time disablement rehabilitation officer of the Ministry of Labour who saw patients likely to be recommended foo discharge from the army during the first two week\$ in hospital, and on at least one subsequent occasion before they left. He was helped not only by the psychiatrist and vocational psychologist, but had the advantage of a report from the employer witt whom the patient had been working while still its hospital. For instance a man who had already seen something of the work of bricklayers, plasterers, etc., on a building site as part of his work therapy, and had done satisfactory work, could be recommended for a Government training with more confidence than a man who wanted a training, say as a plasterer, but had no clear idea of what the work entailed. Our aim was to arrange a definite employment before discharging a patient from hospital, but as the follow-up study shows, we fell far short of this ideal.

\section{Follow-up Study}

A follow-up study was carried out on 100 of our patients. Unfortunately it was impossible, for administrative reasons, to obtain a random sample; of the 107 patients who had a London residence the first 100 to be studied constituted our material. They were visited by a psychiatric social worker from three to five months after discharge ; in 41 cases both patient and relatives were seen, in 10 cases patients only, and in 49 relatives only. The visits were unannounced, which accounts for the number of men away when visited. The psychiatric social 
worker used a standard form drawn up by the psychiatrist as the basis for her enquiries.

In a few cases the relatives were considered to be unreliable informants, though the majority were very helpful. Most appeared to understand the purpose of the visit, and were able to give a good account of the patient's condition. Where the relatives' account seemed to be highly subjective or if they described the patient as no better, or worse, a second visit was made in order to see the man himself, and, if it was considered necessary, further treatment as an out patient was suggested.

The relatives, of course, felt the strain of readaptation just as the man had done. Some reacted badly, producing additional stress for the patient, and complaining that he had become quieter, or more difficult to please, or that he ate more than his share of the family rations. Others showed remarkable insight into the repatriate's difficulties and gave striking accounts of his progress. Two mothers attributed their understanding of their sons' difficulties to the experience they had gained when their prisoner husbands had returned from the world war 1914-18 in a similar condition.

\section{General Result}

The general picture as far as symptoms go was as follows :

$$
\begin{array}{lcccc}
\multicolumn{2}{l}{\text { Completely recovered }} & . . & \ldots & 22 \\
\text { Improved } & . & \ldots & \ldots & 66 \\
\text { Unimproved } & \ldots & \ldots & \ldots & 12 \\
& & & & 100
\end{array}
$$

Those listed as completely recovered declared they were perfectly well, as well as they were before the war. Those unimproved all stated they had got somewhat better during their hospital stay, 'but had again deteriorated when faced with conditions outside ; 4 of the 12 said they were still better than on admission to hospital, while 8 said they were as ill as at any previous time.

The stresses to which these men were subjected upon discharge were inquired into, and housing and work only will be reported here. Housing was a major cause of trouble in nearly 50 per cent. of the cases ; 38 men were living in definitely overcrowded conditions, and more were likely to do so when their families became fully reunited. In several instances the patient was living with his wife, his parents, and a married sister and her children. Six of the 38 admitted to quarrels with the relatives with whom they were compelled to live. Six others, who were not considered actually overcrowded, were unable to get on with relatives or neighbours living in the same house, and were under considerable emotional stress from this source. In few of these cases did there seem any hope of early relief.

Work Resettlement.-The general situation was as follows :

$\begin{array}{llllr}\text { Pre-war jobs .. } & . . & \ldots & 34 \\ \text { New jobs in old trade } & & . . & 18 \\ \text { New trade } . . & . & . . & 40 \\ \text { No work done } . . & . . & . . & 8 \\ \end{array}$

Of those returned to their pre-war jobs, 27 had decided on this course before coming to hospital, some because of the obligation they felt after having had their pay made up by their firms during their absence, rather than for a particular preference for the work itself. Four others had decided to return after interviewing the D.R.O. in hospital, and 1 who had left hospital with other plans in mind had returned in response to family pressure. Two had returned only temporarily, while waiting for vacancies in Government Training Schemes, and 1 of these felt guilty and unhappy in his job as he alleged older employees were being dismissed in order to make room for the return of service men. In all, 28 of the 34 declared they were satisfactorily settled and happy in their work. It was somewhat difficult to discover just how their present work status compared with their pre-war position, as often the relatives did not know, and, in any case, the men had only been at work for a short period. As far as could be judged 6 had improved in status, and 1, who had abandoned work shortly after starting, for health reasons, had deteriorated. Some of those who had improved appeared to be doing extremely well.

The men who had taken new jobs in their old trade were mostly unskilled men who did not qualify for reinstatement owing to the short period they were in their last pre-war job; there were a few who preferred to find new jobs despite the possibility of reinstatement. Eleven of the 18 said they were content, and 5 said they were waiting for a chance to improve their status; 2 had apparently deteriorated.

Of the $\mathbf{4 0}$ men who had embarked upon a new trade, 21 said they were contented in it. A further 5 were hoping soon to improve their status-they were waiting for licences to open businesses, or for partners to be demobilized etc.- - and 2 of these were attending technical schools. In addition 3 were waiting for government training. The remaining 10 were undecided about their jobs, or were discouraged about them; 2 of these had had to 
abandon work for health reasons and were attending out-patient clinics.

Of the 8 men who had done no work, 1 had been in hospital with infectious hepatitis and 1 was attending a civilian resettlement unit. Of the remaining 6 , who presumably had not started for reason of maladjustment of one sort or another, 5 stated they felt much improved, and this statement tallied with the impressions of relative and investigator. Only 1 of them came in the group of 12 unimproved ; 11 of these unimproved men had at least begun work, though some had had to abandon it. Pre-army work history was assessed as satisfactory or the reverse, the latter being characterized by much unemployment, frequent changes in job, or any down-grading of status. Seventeen of our 100 men were classified as having had unsatisfactory prewar histories, but none of the 6 non-starters were amongst them. All 17 had returned to work promptly.

Thus of the total group of 100,60 said they were settled and well contented at their work and a further 16 were looking forward to bettering their condition in the near future. On the other hand, 6 men never started work at all for reasons of maladjustment, and 3 abandoned it because of recurrence of their symptoms. This is a very favourable outcome (compare Lewis, 1943), but we are by no means certain' it will persist, for the reasons now to be given.

Government Training Schemes.-The Government Training Schemes offered a particularly tempting prospect to the repatriated prisoner of war, and 24 of our 100 men made application while in hospital for one or other of the trades in which training was offered. But three months after discharge only 1 single man was in the training he had applied for. Three others had changed the trade and begun training. Three more waited still for their first choice, and 2 had changed the trade and waited for their second choice. Fifteen men had given it up as a bad job, 12 of these being men now engaged in other jobs, and 3 still out of work. The 5 who still waited to train all showed great keeness to do so and between them had a high degree of neurotic symptoms, which could largely be attributed to their unsettled state.

The investigator felt that the delay in starting the course was a definite factor retarding the recovery of those men who had opted for it. Still more were likely to abandon the idea, though not all those who said they no longer wanted to train had actually cancelled the course, and some might have later returned to it. During their period of daily visits to the labour exchange, the patients said they had been given no encouragement whatsoever; on the contrary the Exchanges usually encouraged the men to abandon the idea of training or at least to change to some alternative course where the waiting list was shorter.

At the same time, the labour market was very favourable to the neurotic, and a temporary job with good pay was easy to obtain. These were mostly obtained through a friend or casual acquaintance and very many were in the building trade, with local contractors, and had the additional advantage of being near to the patient's home, whereas the government training often took place at a considerable distance from it. In some cases training involved living in hostels, an arrangement peculiarly repugnant to the neurotic repatriate, with his special desire for the security and protection of the home.

The majority of these men, according to the Ministry of Labour D.R.O. and the psychiatrist in charge of them would have proved good material for training. The training scheme must be said to have failed where these men are concerned, and it is likely that their condition will deteriorate should they become redundant on an overcrowded labouro market in the future. It is at least a possibility that many who could have become skilled workers will, instead, ultimately become drifters among the्व permanent unemployed.

Changes of Mind about Work.-A large number of men, 30, had decided against the plans they had made while in hospital. Fifteen of these were those who had been disappointed over their training courses ; the others, in spite of advice received at the hospital, had found quite different work once they had come into contact with the labour market outside.

The explanations given were all very similar. "I had a friend who knew a man . ..", " a local contractor talked to my father", even " the wife's boss said he had a job going." It was always through direct personal contact that the job was arranged, and it was precisely because of the intimate nature of the arrangement that the men responded so eagerly. In one case the man had already been back at his old job and was feeling unable to carry on owing to the noise of the engineering shop, when a casual acquaintance stopped him in the street and offered him work as a joiner in his building firm. Carpentry had always been the man's hobby, and the arrangement proved a very happy one; the patient recovered his self-confidence and was happy and contented when interviewed.

The majority of jobs obtained in this way were of an unskilled or semi-skilled nature, and though in some cases the change of plan was definitely 0 
advantage to the patient, it may be that in others his ultimate security will turn out to have been jeopardized.

Work Missed through Illness.-The short-term nature of this follow-up makes no statement about the effect of residual illness on working capacity valid. Actually only 8 men of those who returned to work missed over 14 days during this period, but on discharge from the army these men all got two months leave with pay, and though the majority (59) returned to work before this period expired, some hád been at work only a month when visited.

Ministry of Labour Follow-up.-We can to some extent check these results in our sample by reference to a follow-up done by the Ministry of Labour. This consisted of a letter sent to the patient's home three and a half months after his discharge from hospital, and the returns are complete for the six-months period July to December, 1945; only. During this period 687 patients were discharged and 610 , or 90 per cent., were reported as being in work or training, 31 not yet in work, and 8 unfit for work. Replies were not received from the patients in 20 cases and from the local employment exchanges in 18. It seems, therefore, that our sample at best does not greatly misrepresent the facts as to the entire group.

\section{General Discussion}

- From every point of view-clinical findings, physiological results, psychometric tests, and treatment results-these men appear to lie between the normal person and the usual neurotic seen in neurosis centres, and to whom we were accustomed, for example, at Mill Hill Emergency Hospital. Since they were the most sick 1 per cent. of the repatriates, it must follow that the truly neurotically predisposed in the army were either not placed in a position where they were likely to be captured or were unable to survive the rigours of captive life in Germany without dying, or becoming so ill as to be repatriated. As it turned out, our problems had been very similar to those met with in the civilian resettlement units (which were for rehabilitating the non-neurotic repatriate), as we discovered at our first meeting with Wilson (1947) and his associates. It seems that the symptoms of our patients are probably exaggerations of the usual repatriates' reaction, and our previous experience inclines us tó believe they are not confined to prisoner-of-war repatriates. Similarly, it follows that the general lines of treatment we found to be effective with our group may with advantage be followed in dealing with the re-entrance of a small outcast group into a large parent one.

It may be remarked in passing that our " semineurotics" perhaps show a closer relation to the situation of experimental neurosis in animals than do the classical neuroses. Though it is true that such animals may on occasion show the whole gamut of neurotic behaviour, including compulsive acts, rituals, and regressive behaviour, the more usual manifestations in cat (Masserman, 1943), dog (Gantt, 1943), and sheep (Anderson and Parmenter, 1941) are just those seen in our patients. Disturbances of heart rate and respiration occur (the oxygen uptake of sheep following exercise has yet to be investigated), restlessness, irritability, and distrust and dislike of those responsible, as they think (quite rightly, in the animal's case) for their condition. Some animals, be it noted, become shy and asocial as a result of this treatment, and, in the case of sheep, stay apart from the rest of their flock: were they but human, feelings of repressed guilt (about what, in this case?) would undoubtedly be attributed to them.

As in Masserman's cats, it was the threat of return to the situation of conflicting drives, which had initiated the neurosis, that most upset our patients. The cats showed marked anxiety on being returned to the circumstances in which the neurosis-producing situation had occurred; nothing in our patients caused greater symptoms of anxiety, amounting sometimes to panic, than the idea that they would be returned to army service. They mostly believed, as did Jeffrey and Bradford's $(1945-6)$ patients, that they were to be released from further duty as of right ; and it was obvious that, try as they would, they could not but identify the British N.C.O.s (that some had met again for a short time and others only imagined in advance) with their guards, and the army barracks with their prison.

\section{Summary}

1. A description is given of the clinical characteristics, treatment, and follow-up results of repatriated prisoners of war from North-west Europe suffering from neurotic symptoms. These men constituted the most maladjusted 1 per cent. of the 100,000 repatriates.

2. A detailed history and symptomatology was recorded for a sample of 100 of the 811 dealt with. The conclusions reached are that these men had much less constitutional predisposition to neurosis than the usual army neurosis centre case. They were also less ill than such cases. The most common and severe symptoms of these men were the following : lack of concentration, depression, feeling of not belonging since repatriation, shyness in the presence of women, asocial behaviour, fatiguability, breathlessness on effort, effort intolerance, trembling, 
and resentfulness towards authority, in particular the army.

3. Physiological and psychometric tests, reported elsewhere, entirely support the conclusion that these men are "semi-neurotic" and lie between the normal and the usual neurosis centre patient.

4. Both psychiatrists taking the detailed histories related symptoms of depression mainly to external stress, and somatic symptoms to constitutional predisposition. Such a finding should be considered cautiously in view of other evidence referred to.

5. Treatment is described, with special reference to group methods, work therapy outside the hospital, placement by the resident disablement rehabilitation officer, and the important role of nurses in such a centre.

6. A follow-up study of one hundred patients living in the London area was done by a psychiatric social worker, three to five months after discharge. At this time twenty-two patients were completely recovered, sixty-six improved, and twelve unimproved. Ninety-two had returned to work, and sixty were happy and contented in it. Six had not returned for reasons of maladjustment, and three had stopped working because of symptoms. The type of work the patients returned to, and the efficacy of the Government Training Scheme are discussed. It is concluded that though they are now largely well employed, numbers of these men may become unemployed if labour market conditions become less favourable for them.

To Miss M. Croft, who did the follow-up study, we should like to express our appreciation, and our admiration for her excellent and sensitive work and for the way in which she covered, literally, the ground. We also wish to thank Surgeon-Captain R. G. Henderson, Medical Superintendent of the Southern Hospital, Dartford, for his unfailing co-operation during the existence of our unit.

\section{REFERENCES}

Anderson, O. D., and Parmenter, R. (1941). Psychosomat. Med. Monographs, 2, nos. 3, 4.

Eysenck, H. J. (1947). "Dimensions of Personality." London.

Gantt, W. H. (1943). Psychosomat. Med. Monographs, 3, nos. 3, 4.

Jeffrey, M., and Bradford, E. J. G. (1945-6). Brit. J. med. Psychol., 20, 422.

Jones, M. (1944). Amer. J. Psychiat., 101, 292. (1946). Brit. med. J., 1, 533.

Lewis, A. (1943). Lancet, 1, 167.

Masserman, J. H. (1943). "Behaviour and Neurosis." Chicago.

Newman, P. H. (1944). Brit. med. J., 1, 8.

Tanner, J. M., and Jones, M. (1948). J. Neurol., Neurosurg., Psychiat., 11, 61

Torrie, A. (1945). Brit. med. J., 2, 192.

Whiles, W. H. (1945). Ibid., 2, 697.

Wilson, A. T. M., Doyle, M., and Kelnar, J. (1947) Lancet, 1, 735. 